\title{
Investigation and Analysis on the Satisfaction of Master's Education Quality in Chongqing
}

\author{
Hu Weili ${ }^{1}$, Chen Dilong ${ }^{2, *}$ \\ ${ }^{1}$ Graduate School, Chongqing Medical University, Chongqing, China \\ ${ }^{2}$ President Office, Chongqing Three Gorges Medical College, Chongqing, China \\ Email address: \\ 184673716@qq.com (Hu Weili), 775832160@qq.com (Chen Dilong) \\ ${ }^{*}$ Corresponding author
}

\section{To cite this article:}

Hu Weili, Chen Dilong. Investigation and Analysis on the Satisfaction of Master's Education Quality in Chongqing. Higher Education Research. Vol. 5, No. 1, 2020, pp. 17-24. doi: 10.11648/j.her.20200501.14

Received: June 5, 2019; Accepted: January 2, 2020; Published: January 16, 2020

\begin{abstract}
Through large-scale data collection and analysis, in-depth investigation and research, combined with the vertical and horizontal comparison of Postgraduates inside and outside the city, this study will finally show the overall advantages and gaps of graduate education in the form of data. Guided by the macro strategic development of Chongqing's economic and social construction, aiming at the current gap, the corresponding policy education is promoted from the three levels of the state, Chongqing and each training unit, so as to provide intellectual support for comprehensively improving the quality of graduate education in Chongqing. Through consulting relevant documents, define the key concepts such as graduate quality, graduate education quality, graduate training quality and graduate education evaluation; analyze the overall goal of graduate education; understand the current situation of graduate education quality evaluation in relevant provinces and cities; comprehensively collect the current situation of graduate education quality in our city, summarize and sort out the quality quantitative indicators; and influence the quality of graduate education The evaluation factors of quantity are summarized. This paper investigates the basic situation of master's education in Chongqing, investigates and analyses the satisfaction degree of master's training quality of 16 master's training units in Chongqing by means of questionnaires, analyses the relative indexes of higher and lower satisfaction degree of master's training quality in Chongqing, and considers how to further improve the satisfaction degree of master's training quality in Chongqing.
\end{abstract}

Keywords: Master Students, Training Quality, Satisfaction, Investigation and Analysis

\section{Introduction}

In 2010, China's total GDP officially surpassed Japan and became the second largest economy in the world after the United States. This event is of symbolic significance in the course of the great historical rejuvenation of the Chinese nation, which indicates that China's comprehensive national strength and global influence have been further enhanced [1]. While firmly grasping the development opportunities, we should also be soberly aware that the road to development is not smooth, and opportunities always coexist with challenges. In the final analysis, this is the result of the development and competition of international forces. Development and competition are still the theme of the times and the key to solving all problems in China. The core of competition is high-level talents. At present, China has entered the ranks of the major countries of graduate education, but the quality of graduate education has not been internationally recognized. The graduate students trained in our country can not obtain the employment qualification smoothly in developed countries [2]. This situation hinders the internationalization of postgraduate education in China and is not conducive to the realization of the strategic goal of building a strong talent country.

Under the above macro background, the Chongqing Municipal People's Government attaches great importance to the city's graduate education. The Office of Chongqing Academic Degree Committee and Chongqing Education Committee have set up a major research topic on the reform of graduate education and teaching, which is called "Investigation and Research on the Quality of Graduate 
Education in Chongqing" [3]. They have entrusted the Graduate School of Chongqing Medical University to carry out research on the subject, and have conducted research on 16 graduate training Questionnaire survey, trying to find out the basic status of master's education in our city, grasp the main problems of master's education in our city, and further improve the comprehensive competitiveness of master's education in our city.

\section{Contents and Methods of Research}

In March 2013, the office of Chongqing Academic Degree Committee and the Department of Academic Degree Management and Graduate Education of Chongqing Education Committee entrusted the Graduate School of Chongqing Medical University to carry out a survey on the quality of master's training in 16 postgraduate training units in Chongqing. The Graduate School of Chongqing Medical University immediately organized relevant researchers to set up a research group. On the basis of consulting a large number of documents, the members of the research group comprehensively considered four main ideas of Master's education quality, including scientific research achievements, practical training, career orientation and benefit orientation, and combined with the existing questionnaire index system, designed a comprehensive questionnaire on the quality of Master's education in Chongqing.

The first round of survey was conducted from May 1 to May 31, 2013 [4]. Questionnaires, expert interviews, group interviews and seminars were used to obtain the main data and information. The research group conducted a survey on 16 training units of master's degree students in the city. The subjects were mainly divided into master's degree students, master's supervisors, master's education administrators, graduate students and so on. According to the training scale of 16 universities, the number of questionnaires was determined [5]. A total of 4720 questionnaires were sent out and 4262 valid questionnaires were recovered. The effective rate was 90.3\% (Table 1).

Based on the investigation and research work on the quality of master's education in Chongqing, this paper intercepts part of the survey data and analysis reports, and focuses on the analysis of the satisfaction degree of different related subjects of master's education in Chongqing, such as in-school master's students, master's tutors, master's education administrators and some graduate master's students, to the quality of master's education in Chongqing, and uses the above subjects to analyze the quality of master's education in our city. On the basis of the evaluation, this paper considers how to further improve the training quality of Master's degree students in our city.

Table 1. Questionnaire on the Quality of Master's Education in Chongqing.

\begin{tabular}{|c|c|c|c|c|c|}
\hline University/Institute Name & $\begin{array}{l}\text { Questionnaire for } \\
\text { Master Students in } \\
\text { School }\end{array}$ & $\begin{array}{l}\text { Questionnaire of } \\
\text { Master's } \\
\text { Supervisor } \\
\end{array}$ & $\begin{array}{l}\text { Questionnaire for } \\
\text { Master's Graduate } \\
\text { Administrators }\end{array}$ & $\begin{array}{l}\text { Questionnaire for } \\
\text { Graduated Master } \\
\text { Students }\end{array}$ & Total \\
\hline Chongqing University & 500 & 100 & 20 & 50 & 670 \\
\hline Southwest University & 500 & 100 & 20 & 50 & 670 \\
\hline Third Military Medical University & 300 & 100 & 10 & 30 & 440 \\
\hline Chongqing Medical University & 300 & 100 & 10 & 30 & 440 \\
\hline Southwest University of Political Science and Law & 300 & 100 & 10 & 30 & 440 \\
\hline Chongqing University of Posts and Telecommunications & 200 & 50 & 10 & 20 & 280 \\
\hline Chongqing Normal University & 200 & 50 & 10 & 20 & 280 \\
\hline Sichuan International Studies University & 200 & 20 & 10 & 20 & 250 \\
\hline Chongqing university of technology & 200 & 20 & 10 & 20 & 250 \\
\hline Chongqing University of Industry and Commerce & 200 & 20 & 10 & 20 & 250 \\
\hline Sichuan fine arts institute & 100 & 10 & 10 & 10 & 130 \\
\hline University of Logistics & 100 & 10 & 10 & 10 & 130 \\
\hline Party School of Chongqing Municipal Party Committee & 20 & 10 & 10 & 5 & 45 \\
\hline Chongqing Institute of Science and Technology & 10 & 10 & 10 & 0 & 30 \\
\hline Total & 3440 & 760 & 180 & 340 & 4720 \\
\hline
\end{tabular}

\section{A Survey of the Basic Situation of Master Education in Chongqing}

\subsection{Scale of Master's Education}

In 2013, Chongqing Municipal Master's Degree Training Units, authorized First-Level Discipline master's degree points, enrolled 14868 full-time master's students, including 8964 academic degrees, 5704 professional degrees. A total of 44 477 postgraduates, 7369 tutors and awarded master's degrees were enrolled. In terms of scale, our city ranks second among the five western provinces (Sichuan, Chongqing, Yunnan, Guizhou and Tibet), second only to Sichuan, and fourth among the four municipalities directly under the Central Government (Beijing, Shanghai, Tianjin, Chongqing), which is closer to Tianjin.

\subsection{Master's Education Structure}

First, the structure of subject categories. At present, graduate education in Chongqing has covered all 13 subject categories. From the point of view of the students, the proportion of master students in engineering is the highest, reaching $28.77 \%$, followed by literature and medicine. 
Agriculture, philosophy and history accounted for the lowest proportion, $2.52 \%, 1.92 \%$ and $0.6 \%$ respectively. The second is the structure of degree types [6]. The proportion of professional degree in the enrollment scale of master students is $38.36 \%$, which is lower than the national average proportion $(40.32 \%)$. Generally speaking, the scale of professional degree postgraduate education is slightly lower than the national level, and it still needs to be further expanded. Third, the gender structure, the proportion of female students in the school is $50.46 \%, 22443$, in the master's education level, the proportion of female students is slightly higher. Fourthly, the age structure of master's degree students in school is the age group of 23-25 years old, accounting for $73.73 \%$. Among the graduates who study full-time master's degree, the students who work for a short time after graduation are still the main ones.

\subsection{Time Allocation of Master's Education System and Training Link}

At present, some training units in Chongqing have begun to implement flexible education system. The basic education system for master students is two and a half to three years, and most universities are three years [7]. According to the survey data, most of the master students $(61.07 \%)$ think that the two-year system is more suitable for master students, and most of the tutors $(75.99 \%)$ think that the three-year system is more conducive to the cultivation of master students. The opinions of managers are basically the same as those of mentors.

Course learning, scientific research and practical ability training constitute the main link of master's training. The proportion of each link in the process of graduate training can reflect the focus of different degree types of master's training [8]. The survey shows that, as a whole, the proportion of master's course learning is relatively high, with both academic degree and professional degree being 20\%-30\%. The proportion of scientific research of academic degree and master's degree in the whole study time is relatively high, averaging $20 \%-30 \%$. The proportion of practical skills training of professional degree and master's degree students in the whole study time is relatively high, averaging $20 \%-30 \%$
(Table 2)

Table 2. Time Allocation of Master's Education\%.

\begin{tabular}{lll}
\hline Training link & Academic Degree & Professional Degree \\
\hline Course learning & $20-30$ & $20-30$ \\
Scientific research & $20-30$ & $10-20$ \\
Practical Ability Training & $10-20$ & $20-30$ \\
Rest and recreation & $10-20$ & $10-20$ \\
\hline
\end{tabular}

\subsection{Basic Situation of Master Tutors}

From the overall situation of Chongqing, the current implementation of the tutorial system is more traditional, the single tutorial system is more common, with $75.59 \%$ of master students supervised by a tutor. Some colleges and universities have begun to implement the "dual tutorial system" to train master's degree students, that is, a tutor on campus and a senior professional title staff of enterprises and institutions outside the school jointly train master's students. Some colleges and universities have begun to study the introduction of tutorial group system into the training of master's degree students [9].

In terms of the number of Master's supervisors, the number of Master's supervisors in Universities in our city is generally larger, with an average of 5.3 Master's supervisors per Master's supervisor, resulting in less communication time between teachers and students. Among the Master's students surveyed, the average number of teacher-student exchanges per month is very small, and the number of Master's degree students is academic. The number of students was 3.15 and the number of master's degree students was 2.7.

Guiding master's students to write dissertations is one of the main tasks of tutors. Master's students are satisfied with the work of tutors. Most master's students think that tutors help them to write dissertations (Table 3). However, in addition to instructing graduate students to write dissertations, the impact of tutors on the academic career of graduate students is not enough. The survey results show that tutors have a greater impact on their academic attitude, academic integrity and moral accomplishment in the process of their growth, but relatively less help to their academic interest and practical ability.

Table 3. The Assistance of Tutors to Master's Degree Thesis Writing\%.

\begin{tabular}{|c|c|c|c|c|c|}
\hline Different degree types & Greatly & More & Commonly & Less & Very small \\
\hline Academic Degree & 15.58 & 38.23 & 34.84 & 7.27 & 4.08 \\
\hline Professional Degree & 14.51 & 39.07 & 33.97 & 7.50 & 4.94 \\
\hline
\end{tabular}

\section{Investigation and Analysis on the Satisfaction of Master's Education Quality in Chongqing}

The evaluation system of Master's training quality includes professional knowledge level, scientific research level, innovation ability, foreign language level, academic ethics level and so on. Different subjects have different understanding of the evaluation system and different emphasis on the evaluation system. According to the training objectives, training process and basic qualities of high-level talents for master's degree students, combined with the main evaluation indicators used in the national doctoral quality survey carried out by the Academic Degree Committee of the State Council, the Ministry of Education and the Ministry of Personnel in 2007, the research group refined the basic and professional knowledge level, the knowledge level of related disciplines, the level of foreign languages, the ability of innovation, the ability of organization and coordination, and the sense of mission. 12 indicators, such as sense of responsibility, 
academic ethics, scientific research ability, dissertation quality, practical ability and academic integrity level, are used to examine the satisfaction of different subjects to the current quality of master's training in Chongqing.

\subsection{Emphasis of Different Subjects on Evaluation Index of Master's Training Quality}

For master's students, master's students, tutors and managers think that innovation ability, basic and professional knowledge level, scientific research ability are the most important indicators reflecting the quality of master's training. However, the ranking of importance of the three is slightly different [10]. The undergraduates think that the basic and professional knowledge level is the most important, followed by innovation ability, and the third scientific research ability [11]. Teachers and managers think that innovation ability is the most important, basic and professional knowledge level is the second, scientific research ability is the third. This reflects that the master's students think that knowledge level is the key to master's training, and it is difficult for them to have strong innovative ability. Teachers and managers believe that the quality of master's training should also be guided by improving innovation ability (Table 4).

Table 4. The Emphasis of Different Subjects on the Quality of Master's Education\%.

\begin{tabular}{llll}
\hline Evaluation projects & $\begin{array}{l}\text { Questionnaire for Master } \\
\text { Students in School }\end{array}$ & $\begin{array}{l}\text { Questionnaire of Master's } \\
\text { Supervisor }\end{array}$ & $\begin{array}{l}\text { Questionnaire for Master's } \\
\text { Graduate Administrators }\end{array}$ \\
\hline Basic and Professional Knowledge Level & 57.12 & 52.93 \\
Knowledge level of related disciplines & 30.33 & 23.63 & 57.65 \\
Foreign language proficiency & 15.3 & 13.48 & 22.35 \\
Innovation ability & 54.11 & 54.69 & 8.24 \\
Organizational and coordination capabilities & 19.24 & 13.28 & 58.82 \\
Sense of mission and responsibility & 13.5 & 10.74 & 12.94 \\
Academic moral level & 18.48 & 13.87 & 11.76 \\
Scientific Research Ability & 50.06 & 52.34 & 21.18 \\
Dissertation quality & 13.19 & 25 & 50.59 \\
practical ability & 40.27 & 27.34 \\
Academic Credit Level & 13.23 & 16.02 \\
\hline
\end{tabular}

\subsection{A Survey of Master's Satisfaction with the Quality of Self-cultivation}

Overall, Master students are more satisfied with their training quality in academic integrity, ideological and moral level and practical ability, and less satisfied with their innovative ability, sense of mission and responsibility, and knowledge level of related disciplines (Table 5).

Table 5. Self-evaluation of Master's Education Quality\%.

\begin{tabular}{|c|c|c|c|}
\hline Evaluation projects & High & Commonly & Low \\
\hline Basic and Professional Knowledge Level & 39.84 & 55.58 & 4.58 \\
\hline Knowledge level of related disciplines & 26.41 & 65.52 & 8.06 \\
\hline Foreign language proficiency & 31.59 & 60.56 & 7.85 \\
\hline Innovation ability & 22.55 & 63.47 & 13.97 \\
\hline Organizational and coordination capabilities & 32.20 & 60.40 & 7.40 \\
\hline Sense of mission and responsibility & 39.60 & 50.40 & 10.00 \\
\hline Academic moral level & 60.04 & 37.75 & 2.21 \\
\hline Scientific Research Ability & 31.78 & 60.53 & 7.69 \\
\hline Dissertation quality & 42.57 & 54.18 & 3.26 \\
\hline practical ability & 42.08 & 50.10 & 7.82 \\
\hline Academic Credit Level & 43.11 & 50.50 & 6.39 \\
\hline Basic and Professional Knowledge Level & 64.20 & 33.20 & 2.60 \\
\hline
\end{tabular}

\subsection{Higher Satisfaction Index of Master's Students in Chongqing to Their Training Quality}

\subsubsection{Academic Credit Level}

Academic integrity level is the most satisfactory aspect for master students during their study period. $64.2 \%$ of master students think that they perform better, $33.2 \%$ of master students perform generally, and $2.6 \%$ of master students think that they perform poorly in academic integrity [12].

\subsubsection{Ideological and Moral Level}

The survey results show that the ideological and moral level ranks second in all indicators, $60.04 \%$ of the graduates think their ideological and moral level is higher, $37.75 \%$ of the graduates think their ideological and moral level is general, and $2.21 \%$ of the graduates think their ideological and moral level is poor [13]. 


\subsubsection{Practical Ability}

Most of the master's students are satisfied with their practical ability. $43.11 \%$ of the master's students say they have strong practical ability, $50.50 \%$ of the master's students say they are general, and $6.39 \%$ of the master's students say they are poor.

\subsubsection{Dissertation Quality}

Generally speaking, master's students are also satisfied with the quality of their dissertations. $42.57 \%$ of the master's students think that the quality of their dissertations is high, $54.18 \%$ of them think that the quality is general, and only $3.26 \%$ of the master's students think that the quality of their dissertations is low.

\subsubsection{Degree of Learning Engagement}

Master students in our city have a high degree of investment in learning, $42.08 \%$ of them think they are very involved in learning, $50.10 \%$ of them think they are relatively involved in learning, and $7.82 \%$ of them think they are not enough in learning.

\subsubsection{Basic and Professional Knowledge}

The basic and professional knowledge of master's students in our city is relatively solid. $39.84 \%$ of the master's students think that they perform better in this respect. $55.58 \%$ of the master's students think that their performance is average. $4.58 \%$ of the master's students think that they lack basic and professional knowledge.

\subsection{Indicators of Master's Degree of Satisfaction with Self-cultivation Quality in Chongqing}

\subsubsection{Innovation Ability}

Innovative ability is the worst indicator of master's performance. $13.97 \%$ of the graduate students think that they are very lack of innovation ability, $63.47 \%$ of the graduate students think that their innovation ability is general, only $22.55 \%$ of the graduate students think that their innovation ability is strong.

\subsubsection{Sense of Mission and Responsibility}

Master students in our city lack sense of mission and responsibility. $10 \%$ of the postgraduates thought that they did poorly in this respect, $50.4 \%$ thought that they did not perform well, and $39.6 \%$ thought that they had a strong sense of mission and responsibility.

\subsubsection{Knowledge Level of Related Disciplines}

Master students in our city also lack the breadth of knowledge in related disciplines. $8.06 \%$ of the postgraduates thought that they had limited knowledge of related disciplines, $65.52 \%$ thought that they had general knowledge of related disciplines, and $26.41 \%$ thought that they had rich knowledge of related disciplines.

\subsubsection{Foreign Language Proficiency}

The foreign language proficiency of master's students in our city is poor. According to the survey, $7.85 \%$ of the master's students think their foreign language proficiency is low, $60.56 \%$ of the master's students think their foreign language proficiency is average, and $31.59 \%$ of the master's students think their foreign language proficiency is high.

\subsubsection{Scientific Research Ability}

$7.69 \%$ of the postgraduates thought that their scientific research ability was poor, $60.53 \%$ of the postgraduates thought that their scientific research ability was general, and $31.78 \%$ of the postgraduates thought that their scientific research ability was strong.

\subsubsection{Organizational and Coordination Capabilities}

$7.4 \%$ of the postgraduates thought that their organizational and coordinating abilities were poor, $60.4 \%$ thought that their organizational and coordinating abilities were general, and $32.2 \%$ thought that their organizational and coordinating abilities were strong.

\section{Thoughts on Further Improving the Satisfaction of Master's Students to Their Training Quality}

\subsection{Improving the Investment Mechanism of Master's Education}

\subsubsection{Improving the Financial Allocation System and Increasing the Investment in Master's Education}

Aiming at the problems of different central and local allocation systems, unchanged allocation standards for many years and single allocation methods, we should first expand the scope of allocation and arrange comprehensive quota allocation for students. The second is to raise the standard of allocation. According to the level of economic development, price fluctuation and financial situation, a dynamic adjustment mechanism of allocation standards is established to gradually improve the level of allocation. Third, pay more attention to performance. According to the quality of postgraduate training and the level of scientific research, the central finance allocates funds for the education performance of Postgraduates in central colleges and universities, and the schools arrange for the training of Postgraduates independently.

\subsubsection{Establishing and Perfecting the Fee Collection System}

In view of the imperfect Cost-Sharing Mechanism of Master's education, we should first determine the charging standard, clarify the basic principles and considerations for the formulation of Master's tuition standard, and formulate the tuition standard for Master's students in line with the level of regional economic development. Secondly, the management of fees should be strengthened. To clarify the requirements of the standard-setting procedure, the mode of tuition collection and the management of tuition fee income for master students [14]. Third, improve the supporting measures. To formulate and implement relevant policies such as tuition compensation mechanism, grant and loan system, and "three-aid" system.

\subsubsection{Perfecting the Policy System of Grants and Subsidies} Aiming at the problems of single mode and source of 
funding, relatively low standard of funding and different situations in different places, we should give priority to financial input, coordinate self-financing, scientific research funds, student loans, social donations and other funds in accordance with regulations, and establish and improve the policy system of multiple awards and subsidies. Various training units have increased their financial support in schools, encouraged donations to aid schools and attracted social funds.

\subsection{Speeding up the Internationalization of Master's Education}

Firstly, we should establish the concept of internationalization education and provide conceptual guidance for the development of internationalization education activities. By establishing an internationalized concept of running a school, the cultivation of master's students is considered in the context of the whole world. Secondly, it is necessary to establish an international teaching staff to provide a strong guarantee for promoting the internationalization of master's education. Internationalized teachers are the key to the internationalization of education. University teachers play a particularly important role in promoting the internationalization of postgraduate education. If they have the experience of studying and teaching abroad, they can share this experience with students through lectures and seminars, so that postgraduates can be edified. Thirdly, we should pay attention to the internationalization of curriculum provision and provide the carrier for the internationalization of master's education [15]. The curriculum is the intermediary and bridge to realize the training goal of master's degree students. In the course design, we should not only offer courses involving other countries and international issues as far as possible, but also make the courses have international views and open horizons as far as possible. The internationalization of master's courses should not only introduce high-quality teaching resources from other countries in the form of curriculum content, textbook construction, foreign language teaching and curriculum management, but also encourage bilingual teaching, especially increase the introduction and compilation of original textbooks, and impart the latest international theoretical achievements to students. In addition, strengthening mutual recognition of academic qualifications and credits with foreign universities and realizing internationalization of teaching evaluation are important contents of the reform of internationalized curriculum. Today, with the development of information technology, we should also pay attention to and make use of the abundant network curriculum resources abroad. Fourthly, we should strengthen the internationalization of scientific research activities and create a good environment for scientific research and innovation of master's students.

\subsection{Perfecting the Enrollment Examination System and Selecting Top Innovative Talents}

With the increasing number of postgraduate entrance examinations, the system of enrollment and examination for master's students has been paid more and more attention, and it is imperative to reform the examination system. Especially, we should promote the reform of "two-stage system" in the examination of postgraduate enrollment, and strengthen the test of the comprehensive ability of candidates on the premise of guaranteeing the effective inspection of the basic knowledge of candidates. Enlarging the autonomy of enrollment units, expanding the scale of pushing out and exempting students, forming a special selection mechanism for special talents, and improving the selection efficiency of innovative talents are the key directions of the reform of the Master's Enrollment Examination in our city.

\subsection{Strengthening the Cultural Construction of Colleges and Universities and Improving the Academic Moral Level of Master Students}

\subsubsection{Strengthen the Construction of Campus Culture}

Colleges and universities should return to the spiritual home of guiding social ideological trend in concept and ideology, and create an academic atmosphere of "willing to be lonely", "resisting temptation" and "willing to sit on the cold bench". Colleges and universities should always put the construction of academic moral culture in the first place, establish the idea of "reputation first" and build the "pursuit of excellence" College culture.

\subsubsection{Strengthening the Construction of Learning Style and Academic Credit}

Colleges and universities must actively promote the construction of style of study and academic integrity. Strengthen the education of academic norms and academic integrity of master students, strengthen the tutors'guidance to master students and exchange between teachers and students, strengthen the quality control and internal requirements of dissertations, actively use technical means to prevent academic misconduct, formulate clear and strict punishment measures for academic anomie, promote the construction of academic integrity from the system, prevent micro-and gradually, and increase the violation of integrity cost.

\subsection{Strengthen the Management of Training Process and Improve the Quality of Postgraduate Training in an All-round Way}

The process management of master's training should focus on three aspects. First, we should gradually establish a team of managers who are willing to serve the graduate education cause, have a higher level of political theory and policy, have a strong management ability, and dare to explore boldly, so as to achieve a sound organization, a clear division of labor and the implementation of responsibilities. Secondly, we should attach importance to system construction, draw up a set of rules and regulations according to different periods and requirements, and constantly enrich and improve the training system in teaching practice, so as to make the training system more reasonable and standardized. Thirdly, we should strengthen the construction of cadres for postgraduate work at 
the faculty level, and train them in various forms so that they can meet the needs of postgraduate training.

\section{Conclusion}

The higher quality of postgraduate training in Chongqing: academic integrity level is the most satisfactory aspect for postgraduate students during their study period, $64.2 \%$ of them think that they perform better, $33.2 \%$ of them perform generally, and $2.6 \%$ of them think that they perform poorly in academic integrity. The survey results also show that the ideological and moral level ranks the second in all indicators, $60.04 \%$ of the master students think their ideological and moral level is high, $37.75 \%$ of the master students think their ideological and moral level is general, and $2.21 \%$ of the master students think their ideological and moral level is very poor. The survey of master students shows that most of them are satisfied with their practical ability, $43.11 \%$ of them say they have strong practical ability, $50.50 \%$ of them say they are average, and $6.39 \%$ of them say they are poor. On the whole, the quality of master's thesis is also satisfactory. $42.57 \%$ of the master students think the quality of the thesis is high, $54.18 \%$ of the master students think the quality is average, only $3.26 \%$ of the master students think the quality of the thesis is low. The master students in our city are also highly engaged in learning. $42.08 \%$ of the master students think that they are very committed to learning, $50.10 \%$ of the master students think that they are relatively committed to learning, and $7.82 \%$ of the master students think that they are not committed enough to learning. Our city master's basic and professional knowledge is also relatively solid. $39.84 \%$ of the master students think that they perform well in this respect, $55.58 \%$ of the master students think that they perform generally, and $4.58 \%$ of the master students think that they are lack of basic and professional knowledge.

In Chongqing, the quality of postgraduate training is poor: innovation ability is the worst indicator of postgraduate performance. $13.97 \%$ of the master students think that their innovation ability is very poor, $63.47 \%$ of the master students think that their innovation ability is average, only $22.55 \%$ of the master students think that their innovation ability is strong. The master students in our city are lack of sense of mission and responsibility. $10 \%$ of the master students think that their performance is very poor, $50.4 \%$ of the master students think that their performance is average, $39.6 \%$ of the master students think that they have a strong sense of mission and responsibility. The master degree students in our city are lack in the breadth of relevant subject knowledge. $8.06 \%$ of the master students think they have limited knowledge of related disciplines, $65.52 \%$ of the master students think they have general knowledge of related disciplines, $26.41 \%$ of the master students think they have rich knowledge of related disciplines. The foreign language level of master students in our city is poor. According to the survey, $7.85 \%$ of the master students think their foreign language level is low, $60.56 \%$ of the master students think their foreign language level is average, and $31.59 \%$ of the master students think their foreign language level is high. $7.69 \%$ of the master students think that their scientific research ability is poor, $60.53 \%$ of the master students think that their scientific research ability is average, $31.78 \%$ of the master students think that their scientific research ability is strong. $7.4 \%$ of the master students think that their organization and coordination ability is poor, $60.4 \%$ of the master students think that their organization and coordination ability is general, $32.2 \%$ of the master students think that their organization and coordination ability is strong.

\section{Acknowledgements}

This paper is part of the research results of the key topics of the Chongqing Graduate Education and Teaching Reform Research Project, "The Report on the Development of Graduate Education Quality in Chongqing" (No. yjg152029) and "The Research on the Development of Graduate Education Quality in Chongqing in 2016" (No. yjg20162033).

\section{References}

[1] Huang Baoyin. Review and Reflection on the Development of Professional Degree Education in China (I). Degree and Graduate Education, 2007 (06).

[2] Zhao Changlin. Problems in the reform and development of postgraduate education in local colleges and universities. Research on Continuing Education, 2011 (7).

[3] Wu Qidi. Seize the opportunity to deepen reform and improve quality and actively promote the rapid development of professional degree education. Degree and postgraduate education, 2006 (5).

[4] Wang Zhanjun, Li Minglei. Graduate Quality Assessment: Model and Framework. Higher Education Research, 2012 (03).

[5] Ye Shuo, Tu Zhonghua. Strengthen international education to improve the international competitiveness of postgraduates. Degree and postgraduate education, 2010 (04).

[6] Liang Wannian. General practitioners, general practitioners and general practitioners. School Health in China, 2004, 25: 252-256.

[7] Qing Wei. A brief discussion on the current situation and development of general practice education in China. China Health Administration, 2001, 1: 32-34.

[8] Jiang Runsheng, Yang Yuping, Chen Youhua. Current situation and Prospect of general practice education. Journal of Kunming Medical College, 2009, (8): 5-8.

[9] Wang Guangrong, Gong Youlong, Mei Renlang. Methods and principles of health manpower quality evaluation. China Health Management. 2002 (9): 569-570.

[10] Guo Hangyuan, Chi Jufang. Strengthening general practice education to train high-quality general practitioners. Zhejiang Clinical Medicine, 2008, 10 (7): 1006-1007.

[11] Down SM, Marasigan F, Abraham V, et al. Scoring performance on computer-based patient simulations: Beyond value of information. Proc AMIA Symp 1999; 520-524. 
[12] Dato N. M. de Gruijter and Leo J. Th. van der Kamp, Generalizability Theory, Advance in Educational and Psychological Testing: Theory and Applications, 1990: 45.

[13] Yao Dingkang, Zhu Liang and Zhang Huahua. Progress in clinical practice skills examination. Shanghai Higher Medical Education, 2003, (1): 34-37.
[14] Sun Tiye, Zhu Xiguang, Chen Ziqiang, etc. Talking about the influencing factors and Countermeasures of the quality of graduation practice for five-year medical students. Northwest Medical Education, 2005, (1): 34-35.

[15] Dai Zhen, Chen Weiyang. Examination of Practical Skills in Diagnostics. Journal of Practical Medical Technology, 2006, (14): $23-25$. 